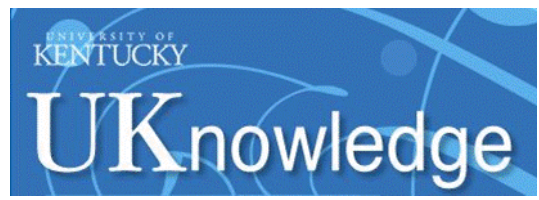

University of Kentucky

UKnowledge

\title{
The Design and Analysis of Large Solar PV Farm Configurations with DC Connected Battery Systems
}

\author{
Oluwaseun M. Akeyo \\ University of Kentucky, ochichikeyo@gmail.com \\ Vandana Rallabandi \\ University of Kentucky, vandana.rallabandi@uky.edu \\ Nicholas Jewell \\ LG\&E and $K U$
}

Dan M. Ionel

University of Kentucky, dan.ionel@uky.edu

Follow this and additional works at: https://uknowledge.uky.edu/peik_facpub

Part of the Power and Energy Commons

Right click to open a feedback form in a new tab to let us know how this document benefits you.

\section{Repository Citation}

Akeyo, Oluwaseun M.; Rallabandi, Vandana; Jewell, Nicholas; and Ionel, Dan M., "The Design and Analysis of Large Solar PV Farm Configurations with DC Connected Battery Systems" (2020). Power and Energy Institute of Kentucky Faculty Publications. 6.

https://uknowledge.uky.edu/peik_facpub/6

This Article is brought to you for free and open access by the Power and Energy Institute of Kentucky at UKnowledge. It has been accepted for inclusion in Power and Energy Institute of Kentucky Faculty Publications by an authorized administrator of UKnowledge. For more information, please contact UKnowledge@lsv.uky.edu. 


\title{
The Design and Analysis of Large Solar PV Farm Configurations with DC Connected Battery Systems
}

\author{
Digital Object Identifier (DOI) \\ https://doi.org/10.1109/TIA.2020.2969102
}

\section{Notes/Citation Information}

Published in IEEE Transactions on Industry Application, v. 6, issue 3.

(C) 2020 IEEE Copyright Notice. "Personal use of this material is permitted. Permission from IEEE must be obtained for all other uses, in any current or future media, including reprinting/republishing this material for advertising or promotional purposes, creating new collective works, for resale or redistribution to servers or lists, or reuse of any copyrighted component of this work in other works."

The document available for download is the authors' manuscript version that is accepted for publication. The final published version is copyrighted by IEEE and available as: O. M. Akeyo, V. Rallabandi, N. Jewell and D. M. Ionel, "The Design and Analysis of Large Solar PV Farm Configurations with DC Connected Battery Systems," in IEEE Transactions on Industry Applications, doi: 10.1109/TIA.2020.2969102 


\title{
The Design and Analysis of Large Solar PV Farm Configurations with DC Connected Battery Systems
}

\author{
Oluwaseun M. Akeyo ${ }^{1}$, Student Member, IEEE, Vandana Rallabandi ${ }^{1}$, Senior Member, IEEE, \\ Nicholas Jewell ${ }^{2}$, Senior Member, IEEE, and Dan M. Ionel ${ }^{1}$, Fellow, IEEE \\ ${ }^{1}$ Department of Electrical and Computer Engineering, University of Kentucky, Lexington, KY \\ m.akeyo@uky.edu, vandana.rallabandi@ieee.org, dan.ionel@ieee.org \\ ${ }^{2}$ LG\&E and KU, Louisville, KY Nicholas.Jewell@lge-ku.com
}

\begin{abstract}
Typically, solar inverters curtail or "clip" the available power from the PV system when it exceeds the maximum ac capacity. This paper discusses a battery system connected to the dc-link of an inverter to recuperate this PV energy. Contrary to conventional approaches, which employ two dc-dc converters, one each for the battery and solar PV system, the proposed configuration utilizes a single dc-dc converter capable of simultaneously operating as a charge controller and a maximum power point tracking (MPPT) tracking device. In addition to improving the overall system capacity factor, increasing the conversion efficiencies and ensuring MPPT stability, the proposed configuration offers a simple solution for adding energy storage to existing PV installations. With this configuration, the excess power that will otherwise be curtailed due to inverter rating limitations is stored in the battery and supplied to the grid during periods of reduced irradiance. Moreover, a systematic methodology for sizing a dc-bus connected battery to minimize total PV energy curtailed was developed using an annual PV generation profile at the Louisville Gas and Electric and Kentucky Utilities (LG\&E and KU) E.W. Brown solar facility at Kentucky. The detailed behavior of the proposed system and its power electronics controls and operations were validated with case studies developed in PSCAD $^{T M} /$ EMTDC $^{T M}$ for variable power generation and $\mathrm{PV}$ output power smoothing.
\end{abstract}

Index Terms-PV, battery, MPPT, PV curtailment, dc-dc converter, charge controller, energy storage, battery sizing, PSCAD.

\section{INTRODUCTION}

The photovoltaic (PV) energy installations are fast-growing both for residential applications, as well as for utility-sized power plants [1]. Solar PV generation is intermittent in nature, and much of the associated research focuses on employing battery energy storage systems (BESS) in order to mitigate this inherent limitation. Power electronic devices play major roles in PV and BESS integration, fulfilling multiple functions including ac-dc transformation, PV maximum power point tracking (MPPT), and battery charge control [2].

Analyses have shown substantial benefits of single-stage grid-connected PV systems over two-stage PV systems, some of which include: lower cost, smaller system size, and higher efficiency [3]-[5]. Configurations with PV systems incorporating BESS typically introduce two additional dc-dc converters, with losses in the supplementary components [6]-[9]. Compared to hybrid PV and battery systems presented in [10]-[12], the proposed configuration, which requires only one dc-dc converter in addition to the grid connected inverter, constitutes Authors' manuscript version. The final published version is copyrighted by IEEE and availa Notice. "Personal use of this material is permitted. Permission from IEEE must be obtained for all other uses, in any current or future media, including reprinting/republishing this material for advertising or promotional purposes, creating new collective works, for resale or redistribution to servers or lists, or reuse of any copyrighted component of this work in other works." a simple and potentially cost effective solution for integrating BESS with conventional PV systems.

Other configurations for battery integrated PV systems using a single dc-dc converter have been presented in literature. In [13], the battery is directly connected to the dc-link of a two-stage converter, which ensures simplicity, but leads to additional losses in the dc-dc converter when the battery is not operational, further affecting the battery over-voltage protection and the effectiveness of the control for the battery charge and discharge operations.

This paper introduces a configuration for integrating BESS with multi-MW grid-connected PV systems, in which the battery is connected to the dc-link of the PV inverter via a dc-dc converter, which simultaneously serves as a charge controller and MPPT device. An approach for determining the ratings of a BESS connected to the dc-bus of an experimental PV system is proposed. This work is an expanded follow-up to a previous conference paper by the same group of authors [14]. Additional contributions include detailed calculations of curtailed solar energy due to inverter rating limitations, the development of a sizing approach for the battery to maximize solar energy utilization based on annual solar PV generation data from the LG\&E and KU site.

The proposed configuration is compared with other established setups including the LG\&E and KU E.W. Brown universal solar facility system, wherein the PV array and BESS are connected to the grid through individual inverters, as described in the second section of this paper. Section III presents the modeling of a simplified BESS integrated PV system and a general approach for battery sizing. Sections IV and V describe the proposed system components and control. Sections VI and VII include a comprehensive examination of the proposed configuration and controls for variable power generation and PV output power smoothing, which was simulated on a sped-up timescale using the $\mathrm{PSCAD}^{T M} / \mathrm{EMTDC}^{T M}$ software.

\section{BATTERy INTEGRATED PV Systems}

Battery energy storage systems may be connected to either the ac or dc terminals of a grid-tied PV system. The ac connected battery units, which require their inverter, introduce the possibility of having an independent operation of the BESS and PV systems as well as the ease of integrating BESS into an existing PV system [15], [16]. However, the configuration is 


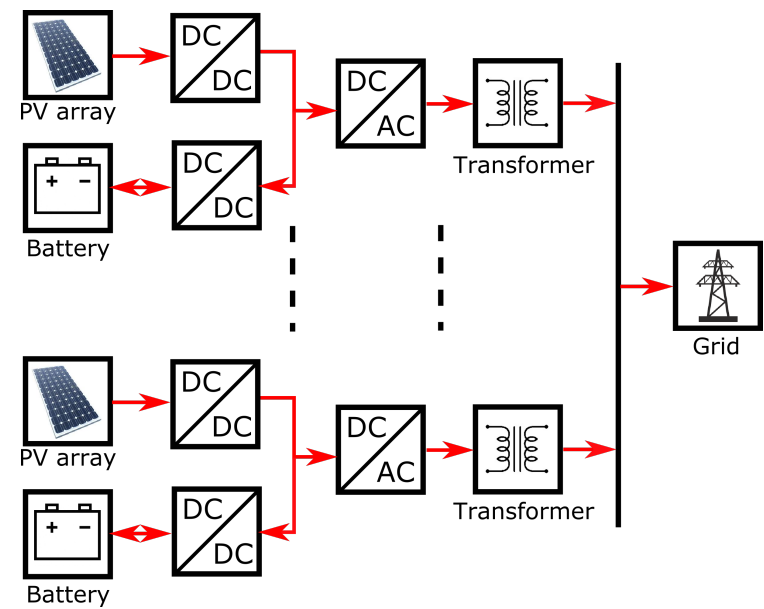

(a)
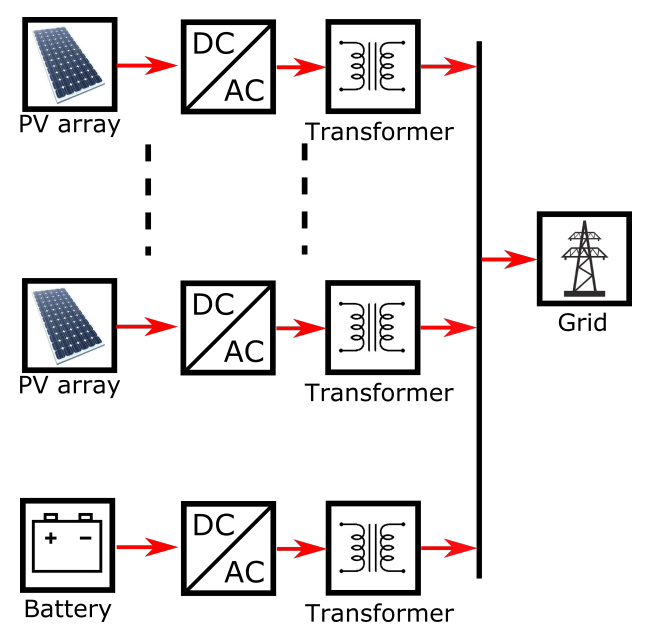

(b)

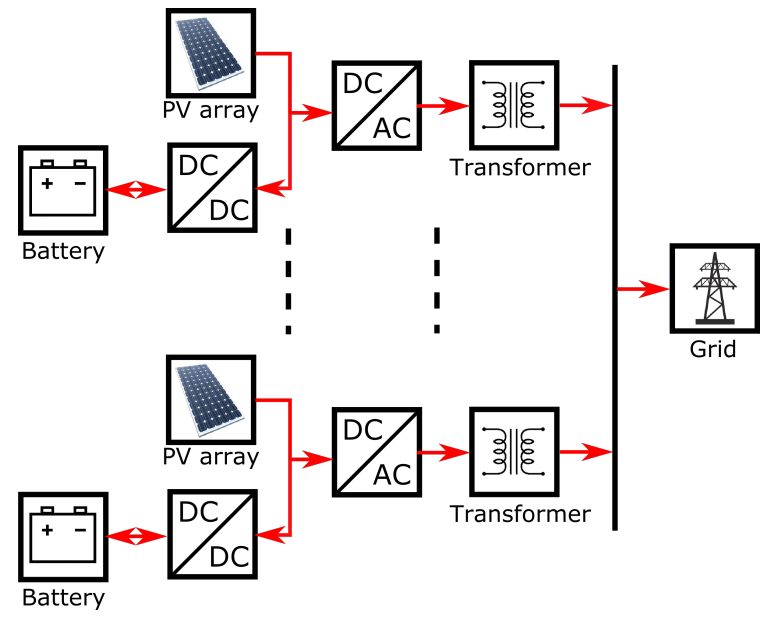

(c)

Figure 1. Example configurations of multi-MW PV system with BESS: (a) Conventional system with multiple dc-dc converters for MPPT and charge control, (b) field implemented system with BESS connected to the grid via independent inverter, (c) proposed system with single dc-dc converter for MPPT and charge control. These systems may also be connected to the grid without a transformer. less efficient, since power needs to flow through two converters when charging the battery with the PV power.

The dc rating for utility-scale PV is typically higher than its ac-rated capacity for multiple reasons including, meeting the minimum inverter dc-bus voltage for MPPT when irradiance is limited, and to maximize the inverter utilization factor as well as system capacity factor. Hence, power is curtailed during periods of surplus irradiance, resulting in poor solar utilization and substantial energy loss, especially in sites with high solar potential [17].

The conventional PV system integrated with a dc-connected BESS includes a PV array connected to a dc-ac inverter via a dc-dc converter for maximum power point tracking (MPPT) and a battery unit connected to the inverter dc-bus via another dc-dc converter operating as a charge controller [18]-[20] (Fig. 1a). Alternatively, the E.W. Brown solar demonstration site by LG\&E and KU houses multiple PV array sections, each connected to the grid via individual dc-ac converters and a battery unit connected to the grid via an independent bidirectional dc-ac converter (Fig. 1b). This experimental facility PV system is divided into 10 sections with each rated for $1 \mathrm{MW}$ with a 1.4:1 dc to ac ratio, hence, totally, up to $4 \mathrm{MW}$ of power is curtailed at rated irradiance.

The multi-MW PV system configuration proposed in this paper is divided into multiple modular sections, where each includes a PV array, battery unit, bidirectional dc-dc converter, two-level grid-connected inverter and transformer (Fig. 1c). The dc-dc converter operates simultaneously as a charge and as an MPPT controller by varying the charge/discharge power of the battery bank to maintain the PV array at the voltage corresponding to its MPP. This configuration allows the battery integrated PV system to operate as a single-stage PV system during periods when the battery is not operational. Also, the proposed configuration can be used to improve the overall system stability of the PV system by constantly maintaining the PV array at its MPP reference voltage during periods of excess irradiance.

\section{Methodology for Sizing the BESS}

The PV system dc output power is represented as a function of its irradiance and cell temperature. The calculated dc power is expressed as

$$
P_{d c S}=\left(\frac{\gamma}{1000} \cdot P_{r 1}\right) \times\left(-\frac{0.41}{100} T_{\text {cell }}+1.1025\right)
$$

where $P_{d c S}$, represents the available PV array dc power; $P_{r 1}$, the rated PV array dc power; $\gamma$, the system irradiance calculated as the average plane of array (POA) irradiance from two weather stations located on the PV farm; $T_{\text {cell }}$, the cell temperature estimated as the average temperature from 40 thermometers located at back of selected PV modules distributed across the PV farm (Fig. 2). The expression for $P_{d c S}$ also accounts for the PV modules $-0.41 \% /{ }^{\circ} C$ maximum power temperature coefficient. 


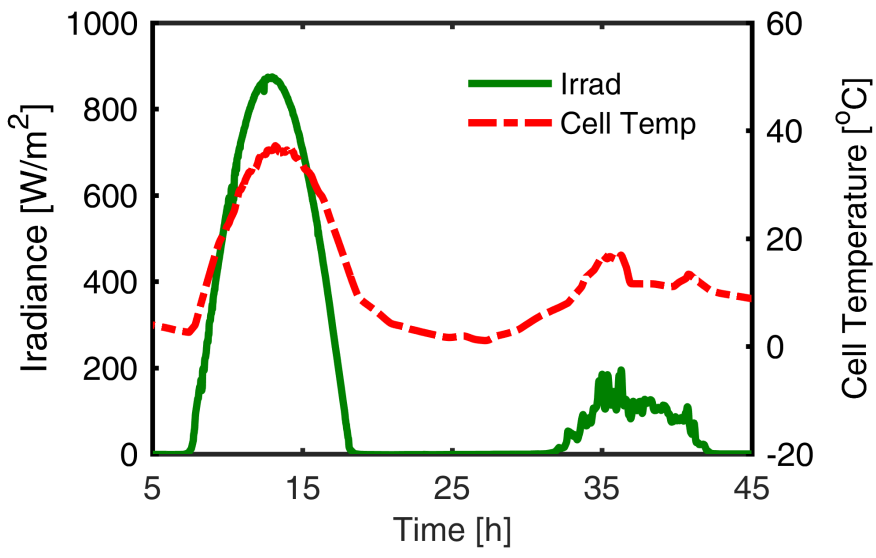

Figure 2. PV system irradiance and cell temperature retrieved from the experimental facility for two example consecutive days. The cell temperature is measured as the average from the back of 40 solar modules distributed across the 45 acres PV farm and the irradiance is measured as the average from two weather stations.

The amount of power supplied to the grid from the PV system is limited by the ac rating of its inverter. Hence, the power supplied to the grid $\left(P_{g S}\right)$ is expressed as:

$$
P_{g S}= \begin{cases}P_{d c S} & P_{d c S}<P_{r 2} \\ P_{r 2} & \text { otherwise }\end{cases}
$$

where $P_{r 2}$ is the inverter rated power. In contrast, for systems with dc connected BESS, additional power from the PV array that will otherwise be curtailed during periods of excess irradiance due to inverter ac specifications may be stored in the BESS. A simplified expression for the power flow in the BESS is described as

$$
P_{b a t t S}=\left\{\begin{array}{ll}
P_{r 2}-P_{d c S} & 0<P_{r 2}-P_{d c S}<P_{r b} \\
P_{r b} & P_{r 2}-P_{d c S} \geq P_{r b} \\
0 & \text { otherwise }
\end{array},\right.
$$

where, $P_{b a t t S}$, is the battery output power and $P_{r b}$, is the BESS rated power. It may be noted that (3) only describes battery charging operations. The PV system ac output power retrieved from the $10 \mathrm{MW}_{a c}$ experimental facility $\left(P_{g E}\right)$ was compared with the calculated $P_{g S}$ for two consecutive sample days with and without excess irradiance, respectively (Fig. $3)$. The battery is controlled to stop charging when its state of charge (SOC) reaches the maximum specified value.. For simplicity, factors such as power electronics and battery round trip efficiency are not considered in this study.

The amount of PV energy curtailed daily varies with different seasons of the year. The daily curtailed PV energy in the absence of dc connected storage is calculated as:

$$
\lambda_{f}=\int_{t 0}^{t 1}\left(P_{d c S}-P_{g S}\right) d t
$$

where, $\lambda_{f}$, is the PV energy curtailed on day $f$; $t$, is time; $t 0$ and $t 1$, are PV curtailment start and end times of the day, respectively. $\lambda_{f}$ was evaluated for the example year with the experimental data retrieved from the $\mathrm{LG} \& \mathrm{E}$ and $\mathrm{KU} 10 \mathrm{MW}_{a c}$ PV system and the peak curtailed PV energy was observed

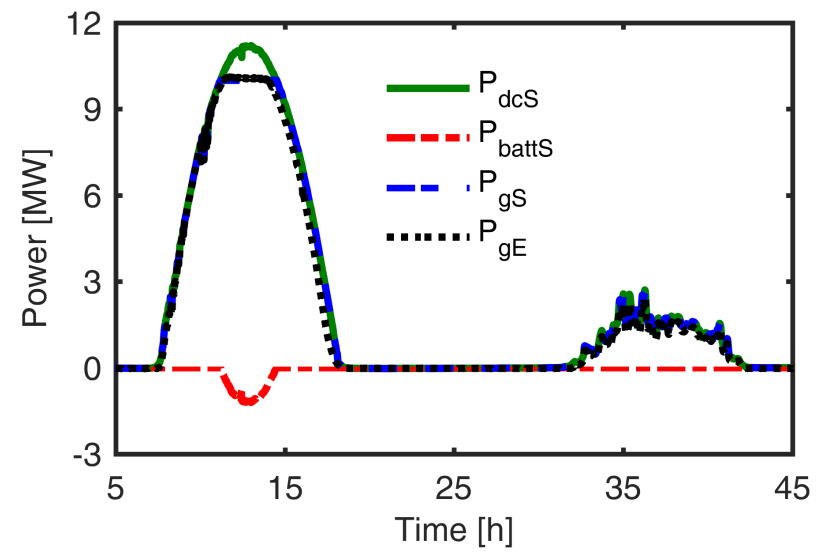

Figure 3. Experimental $\left(P_{g E}\right)$ and simulated $\left(P_{g S}\right)$ PV system output power for two example days validating the simplified PV system model and estimating the curtailed power. $P_{d c S}$ represents the available dc power and $P_{b a t t S}$ represents the power available for storage. A negative sign indicates power flow into the battery.

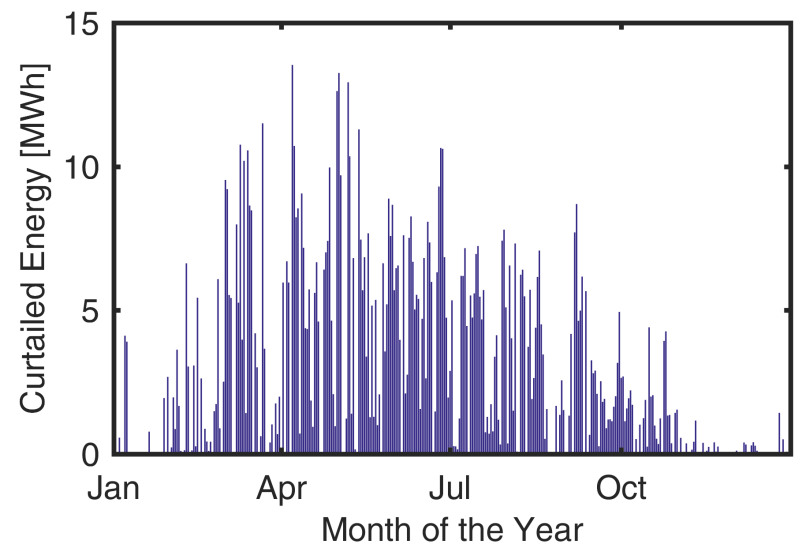

Figure 4. Daily curtailed energy comparison over one year. The solar panels are oriented to peak over the summer, hence, the maximum curtailed energy occurs between April and May.

during the spring period between April and May (Fig. 4). The distribution of the daily PV system energy curtailed was evaluated, in order to establish the size and need for energy storage connected to its dc-bus. It was observed that on most days, the curtailed energy was less than 2MWh (Fig. 5). This indicates that the PV curtailed energy can be reduced significantly by using a relatively small scale BESS rated for $2 \mathrm{MWh}$

Battery energy storage systems are typically sized in terms of power rating and energy storage capacity. A large battery would lead to a reduction in curtailed energy, but become prohibitively expensive. Therefore the minimum battery size which reduces annual curtailed energy is determined. For simplicity, it is assumed that the battery was discharged to its minimum state of charge (SOC) at the start of each day and charges during periods of excess irradiance provided that its cumulative stored energy is less than the rated energy capacity and the SOC is below the specified maximum limit. The annual PV energy curtailed is computed as: 


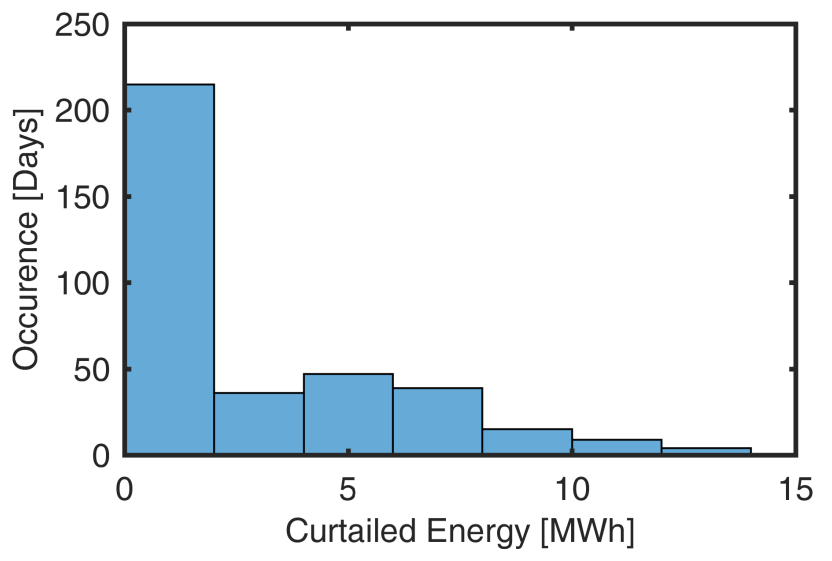

Figure 5. Daily curtailed power distribution over one year. The daily curtailed energy is less than $2 \mathrm{MWh}$ for most of the year and greater than $8 \mathrm{MWh}$ for less than 40 days.

$$
C_{y r}=\sum_{f=1}^{365}\left(\lambda_{f}-E_{b f}\right), \quad \text { where } \quad E_{b f} \leq E_{r b},
$$

$C_{y r}$, represents the annual curtailed energy; $E_{b f}$, the total energy stored in the battery on day $f$; and $E_{r b}$, the battery energy capacity. The value of $C_{y r}$ was computed for multiple $P_{r b}$ and $E_{r b}$ combinations at $20 \mathrm{~kW}$ and $60 \mathrm{kWh}$ intervals, respectively, and the results are plotted (Fig. 6).

For the analyzed example year and case study considered, it can be observed that the desired energy curtailment can be achieved with different battery rating combinations and approximately 1:3 BESS power to energy ratio is the minimum rating combination for a specified $C_{y r}$. Also, it is observed that increasing the BESS size above 2MW/6MWh, does not lead to a significant reduction in the amount of energy curtailed (Fig. 6).

In the case of the field implemented $14 \mathrm{MW}_{d c} / 10 \mathrm{MW}_{a c}$ PV system and example year considered, up to 360MWh of energy curtailed may be retrieved if a 1MW BESS capable of storing up to $2 \mathrm{MWh}$ were connected and distributed across the dc-buses of all PV sections. Since BESS typically have a limited SOC operation range, the recommended battery energy capacity may need to be oversized accordingly. Although, the BESS is primarily sized to reduce the annual curtailed PV energy, it should be noted that its rating is still sufficient for satisfactory grid ancillary services such as, PV power smoothing, frequency regulation, constant power production, and energy arbitrage, some of which are demonstrated in the subsequent sections.

\section{SyStem CONFIGURATION AND COMPONENTS}

Battery energy storage system(s) are expected to play a significant role in the integration of renewable energy sources into the future electric grid. Typical field implementation of Multi-MW PV systems exists as single-stage systems, which includes multiple sections of PV arrays interfaced with the grid via a dc-ac converter capable of performing MPPT. The

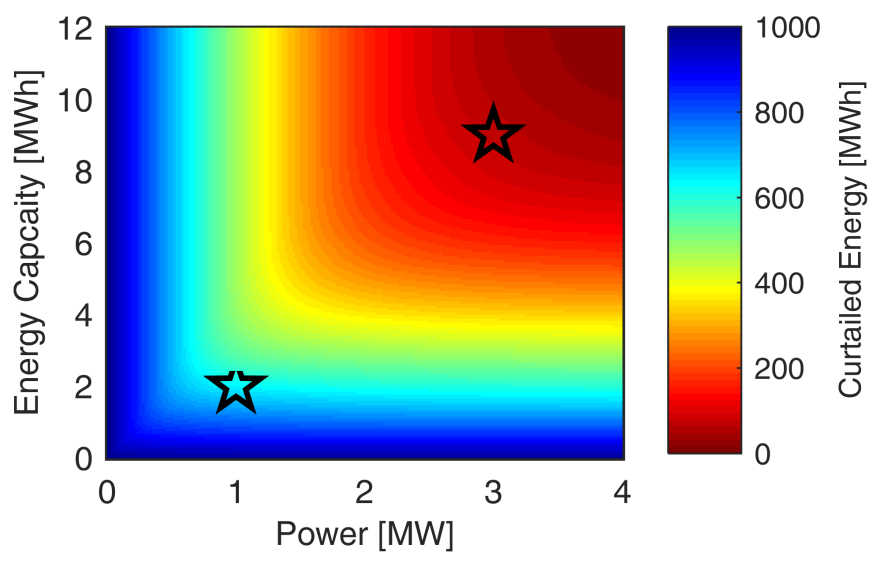

Figure 6. Annual PV energy curtailed for multiple dc connected battery power and energy ratings. For the example considered, up to $1 \mathrm{GWh}$ energy may be curtailed without a dc connected battery.

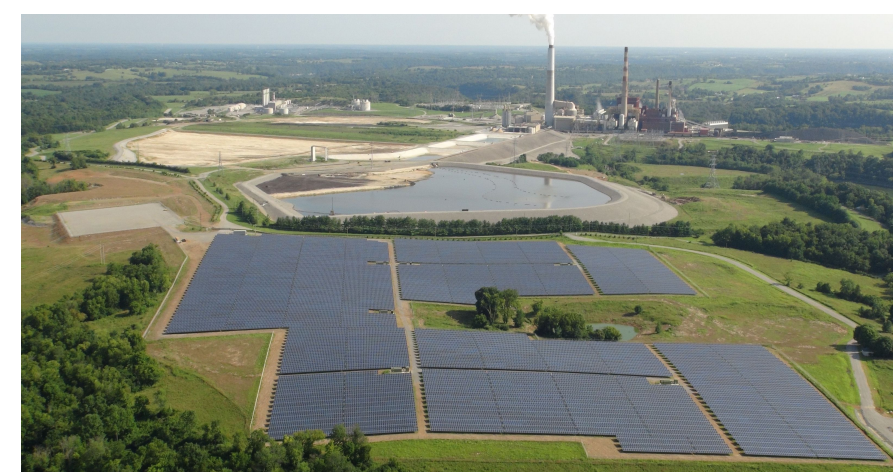

Figure 7. The LG\&E and KU E.W. Brown universal solar facility, which houses a $14 \mathrm{MW}_{d c} 10 \mathrm{MW}_{a c} \mathrm{PV}$ system. The PV system is divided into ten sections with each rated $1 \mathrm{MW}_{a c}$.

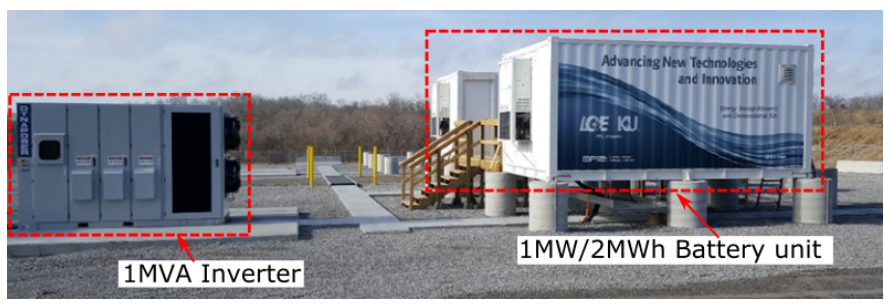

(a)

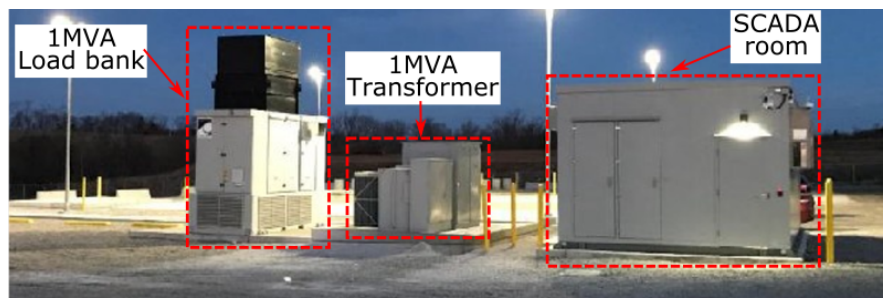

(b)

Figure 8. The battery energy storage system (BESS) setup at E.W Brown LG\&E KU facility rated $1 \mathrm{MW} / 2 \mathrm{MWh}$. (a) Two parallel battery container units are connected to the grid through a bidirectional dc-ac converter, (b) SCADA room for high resolution data management and system control. The experimental facility may be operated in the islanded mode with a 1MVA load bank connected to the secondary side of the transformer. 
Table I

MAIN SPECIFICATION FOR 10MW PV POWER PLANT

\begin{tabular}{lrr} 
& Experimental & Proposed \\
\hline AC rated power (MW) & 10.00 & 10.00 \\
Clear day capacity factor (\%) & 38.91 & 44.50 \\
Clear day PV energy (MWh/section) & 9.34 & 10.68 \\
PV smoothing Battery usage (MWh/section) & 0.40 & -0.74 \\
Annual energy output (GWh) & 19.32 & 20.32 \\
Annual capacity factor (\%) & 22.05 & 23.19 \\
Max. PV array dc power & inverter rating & PV rating \\
Battery charge efficiency & $\eta_{i n v} \times \eta_{i n v}$ & $\eta_{d c d c}$
\end{tabular}

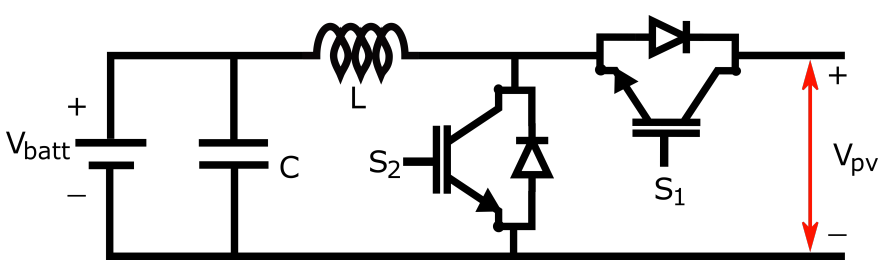

Figure 9. The battery unit connected to the PV array and inverter dc-link through a bidirectional converter, where switch $S_{1}$ and $S_{2}$ are used to regulate the battery charge and discharge current, respectively. proposed configuration may be used to enhance the operation of these existing systems by connecting a battery pack via a bidirectional dc-dc converter to the existing inverter dc link. Depending on the power and energy rating of the integrated BESS, the proposed system may be used to perform operations such as PV output power smoothing, PV constant power production, and peak shifting.

The field implemented PV system consist of ten PV arrays, each made up of 19 Jinko JKM315P-72 PV modules connected in series and an average of 236 module strings in parallel. An equivalent PV array was modeled in $\mathrm{PSCAD}^{T M} / \mathrm{EMTDC}^{T M}$ with each $315 \mathrm{~W}$ PV panel rated at $46.75 \mathrm{~V}$ open circuit voltage and 9.02A short circuit current. The equivalent circuit of the PV cell was modeled based on

$$
i=i_{g}-i_{o}\left[\exp \left(\frac{v+i R_{s r}}{n \mathrm{~K} T_{c} / q}\right)-1\right]-\left(\frac{v+i R_{s r}}{R_{s h}}\right),
$$

where, $i$ represents the cell output current; $i_{g}$, the component of cell current due to photons; $i_{o}$, the saturation current; $\mathrm{K}$, the Boltzmann constant $\left(\mathrm{K}=1.38 \times 10^{-23} j / K\right)$; $q$, the electron charge $\left(\mathrm{q}=1.6 \times 10^{-19} \mathrm{C}\right) ; \mathrm{v}$, the output voltage; $T_{c}$, the cell temperature; $R_{s h}$, the shunt resistance and $R_{s r}$, the series resistance.

The field implemented energy storage site consists of two shipping containers (Fig. 8) with multiple Li-ion LG Chem battery modules, each rated for $51.8 \mathrm{~V} / 126 \mathrm{Ah}$ connected in series and parallel to make up a $1 \mathrm{MW} / 2 \mathrm{MWh}$ battery pack connected to the grid through an independent inverter. The proposed system was modeled with a $0.35 \mathrm{kV}$ nominal voltage battery, which was developed as a non-linear voltage source with open-circuit voltage, $E$, given as:

$$
E=E_{0}-K \cdot \frac{1}{S O C}+A \cdot e^{-B \cdot Q(1-S O C)},
$$

where $E_{0}$ is battery constant voltage, $K$ is polarization voltage, $Q$ is battery capacity, $A$ is exponential zone amplitude, $B$ is exponential zone time constant inverse and $S O C$ is the battery state of charge.

\section{Power Electronics And Controls}

The proposed system requires a dc-dc converter for the battery power flow control in addition to the inverter which interfaces the PV system with the ac grid. In this study, a bidirectional Buck/Boost converter topology (Fig. 10), which typically includes two switches, inductor, and capacitors is employed as a charge controller capable of regulating power flow with the battery. The PV system is connected to the grid through a two-level inverter, a widely available technology that is relatively low-priced with well-established controls and has been demonstrated to be reliable for small inverters below 1MW [21]. The BESS and dc-dc converter offer a means for capturing PV energy that would otherwise be curtailed. This stored energy can be used potentially for PV smoothing and grid ancillary functions.

The system is capable of operating in different modes, which are based on the battery power flow direction or its availability. Also, the proposed configuration allows the power sources to operate effectively and independently of one another. The inverter employs a voltage oriented control scheme in which its active and reactive current components are calculated as a function of $P_{r e f}^{*}$ and the reference reactive power of the system $\left(Q_{r e f}^{*}\right)$ as follows:

$$
i_{d}^{*}=\frac{2}{3} \frac{P_{r e f}^{*}}{v_{d}}, \quad i_{q}^{*}=\frac{2}{3} \frac{Q_{r e f}^{*}}{v_{q}},
$$

where, $v_{d}, v_{q}$ and $i_{d}^{*}, i_{q}^{*}$, are d-q reference frame voltage and currents, respectively.

Mode I: This is the preferred mode of operation, in which the battery charges with the surplus available power. In this operation mode, the ac set power, $P_{r e f}^{*}$ may be calculated as a function of the available PV energy, in which the PV system is expected to operate at its MPP at all times. During periods of excess irradiance or conditions when the ac system rating is less than the available PV power, the battery dcdc converter is operated in Buck (charging) mode, where it ensures MPPT stability by maintaining the PV array terminal voltage at its MPPT reference. In buck mode, pulses to switch $S_{1}$ are modulated to charge the battery with the excess power required to maintain the PV array terminal voltage at MPP when greater than the MPP reference. Hence, the converter current during charge is given as:

$$
i_{b(c)}=\frac{\left(i_{p v}-i_{d c}\right)}{\left(V_{M P P T}-V_{p v}\right)\left(K_{p s}+\frac{K_{i s}}{s}\right)},
$$

where $i_{b(c)}$ is the battery charging current; $V_{M P P T}$, the reference MPP voltage; $V_{p v}, \mathrm{PV}$ array terminal voltage; $i_{d c}$, inverter dc current $P_{r e f}^{*} ; K_{p s}$ and $K_{i s}$, PI controller constants. The battery may also be operated in this mode during period of PV unavailability, in which $P_{r e f}^{*}$ is calculated as the amount of ac power from the grid and the dc-dc charges with corresponding current required to regulate the dc-link voltage at specified value.

Mode II: During periods when $P_{r e f}^{*}$ is greater than the available PV power, due to shading for example, the battery 


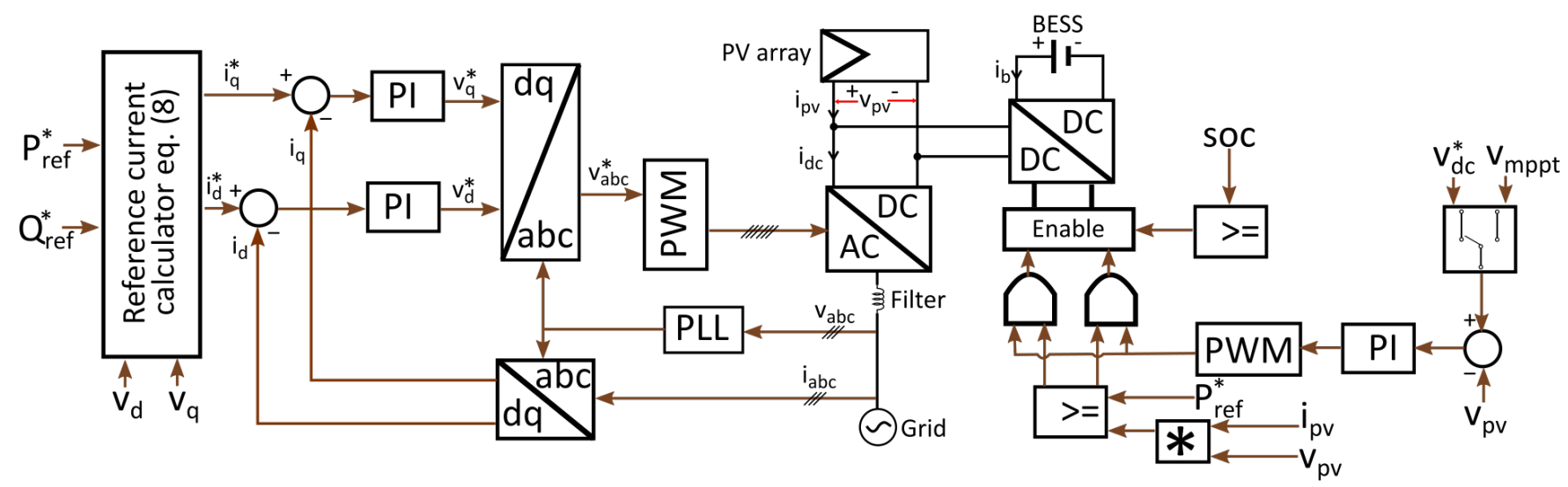

Figure 10. Proposed system schematic and configuration control scheme. The BESS controller charges when $P_{r e f}^{*}$ is lower than the PV output power $\left(i_{p v} \mathrm{x} v_{p v}\right)$. The BESS control is disabled or discharge based on the BESS converter control so that battery supplies or absorbs the amount of power required to maintain the PV array voltage $\left(V_{p v}\right)$ at the voltage corresponding to its $\mathrm{MPP}\left(V_{M P P T}\right)$.

can be used to supply the power deficit. In this case, the dc-dc converter is operated in boost mode, and the duty cycle for switch $S_{2}$ is regulated to ensure the PV array is operating at MPP, while the battery supplies the deficit power. The dc-dc converter current during discharge is expressed as:

$$
i_{b(d)}=\frac{\left(i_{d c}-i_{p v}\right)}{\left[1-\left(V_{M P P T}-V_{p v}\right)\left(K_{p s}+\frac{K_{i s}}{s}\right)\right]},
$$

where, $i_{b(d)}$ is the battery discharge current.

The battery may also be operated as an independent BESS storage system capable of directly interacting with the grid. During discharge, while the battery is above its minimum SOC, the dc-dc converter switches to constant voltage mode, in which it discharges in order to maintain the dc-link voltage at its reference value $\left(V_{d c}^{*}\right)$. The reference dc-link voltage should be greater than the peak ac voltage during discharge and expressed as:

$$
V_{d c}^{*}>\sqrt{V_{d}^{2}+V_{q}^{2}} \text {. }
$$

Hence, the battery discharges when the dc-link voltage is less than $V_{d c}^{*}$ and switch modes to charge when otherwise.

Mode III: The system operates in this mode when the battery SOC is beyond operation range or unavailable. The setup is operated as a single stage PV system, in which the BESS is disconnected from the dc-link and the inverter maintains the PV array at its MPP reference as long as the available PV power is smaller than the ac rating. In this mode, $P_{r e f}^{*}$ is expressed as:

$$
P_{r e f}^{*}=\left(V_{M P P T}-V_{p v}\right)\left(K_{p i}+\frac{K_{i i}}{s}\right),
$$

and the inverter reference active current components as:

$$
i_{d}^{*}=\frac{2}{3} \frac{\left(V_{M P P T}-V_{p v}\right)}{v_{d}}\left(K_{p i}+\frac{K_{i i}}{s}\right),
$$

where, $K_{p i}$ and $K_{i i}$ are the PI controller constants for the dcac converter. It may be noted that in this case, as the inverter capacity is less than the PV dc rating, excess power, otherwise stored in the battery, will need be curtailed during periods of excess irradiance.
Detailed calculations on the filter inductor, and capacitor sizing for this configuration are beyond the scope of this study. Hence, the capacitors connected across the battery terminal and the inverter dc-link, and the dc-dc inductors were sized to be large enough to absorb the ripple currents and ensure minimum voltage variation based on a simplified systematic analysis.

Typical Multi-MW inverters are divided into identical modular power blocks, which are cascaded and connected in parallel to the ac grid. The field implemented system includes central inverters, which are based on automatic redundant modular multi-master systems, where each module is rated for 200kVA to 240kVA [22]. While switch selection is not the focus of this research, the proposed configuration may be developed with IGBT switches rated for power less than 1MVA. This configuration leads to an increase in system efficiency when charging the battery with PV power, compared to the conventional approach with losses in two dc-dc converters and the experimental setup with losses in the PV and BESS inverters. When operated in mode 2 , there is a slight reduction in the proposed system battery round trip efficiency due to the losses in the dc-dc converter, compared to the experimental setup, where the PV and BESS have independent inverters. Generally, due to the reduced amount of switching devices, dc-dc converters have higher efficiencies when compared to dc-ac converters [23].

\section{Proposed System Validation}

The performance of the proposed and field implemented systems were compared via simulation studies, where the irradiance data used was calculated as the average of the data from two weather stations on the LG\&E and KU 10MW universal solar facility on a clear day. The PV cell temperature was estimated as a function of the measured ambient temperature. The field implemented system PV array is rated $14 \mathrm{MW}_{d c}$ with $10 \mathrm{MW}_{a c}$ inverters which are operated for maximum power transfer from the PV array. However, during periods of surplus irradiance, when the inverter power rating is insufficient to transmit the available PV power, the system switches to the constant power mode, where excess power is curtailed. 


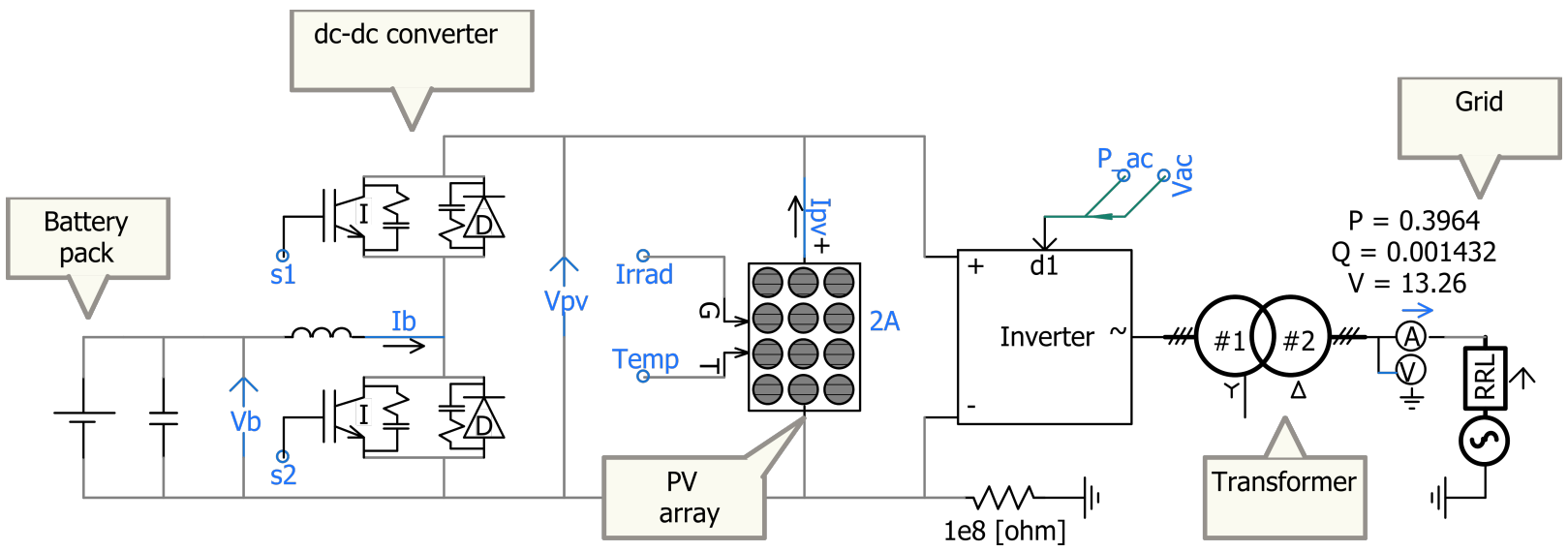

Figure 11. The power circuit diagram in the PSCAD ${ }^{T M} /$ EMTDC $^{T M}$ software environment for a single unit of the proposed system in Fig. 1c, where a constant voltage source is used to represent the grid.

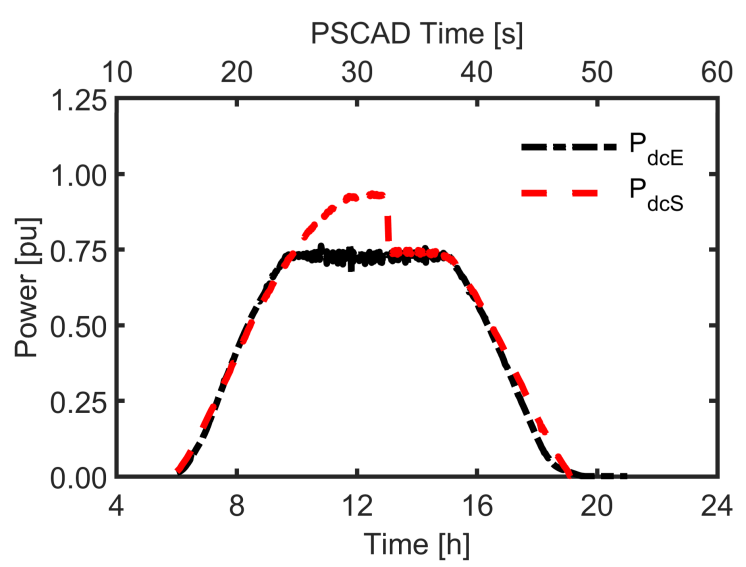

Figure 12. PV array dc output power for the proposed $\left(P_{d c S}\right)$ and field implemented $\left(P_{d c E}\right)$ setups. Due to BESS unavailability at approximately $13 \mathrm{~h}$, the proposed system also curtails excess power during periods of surplus irradiance. $P_{\text {base }}=1.4 \mathrm{MW}$.

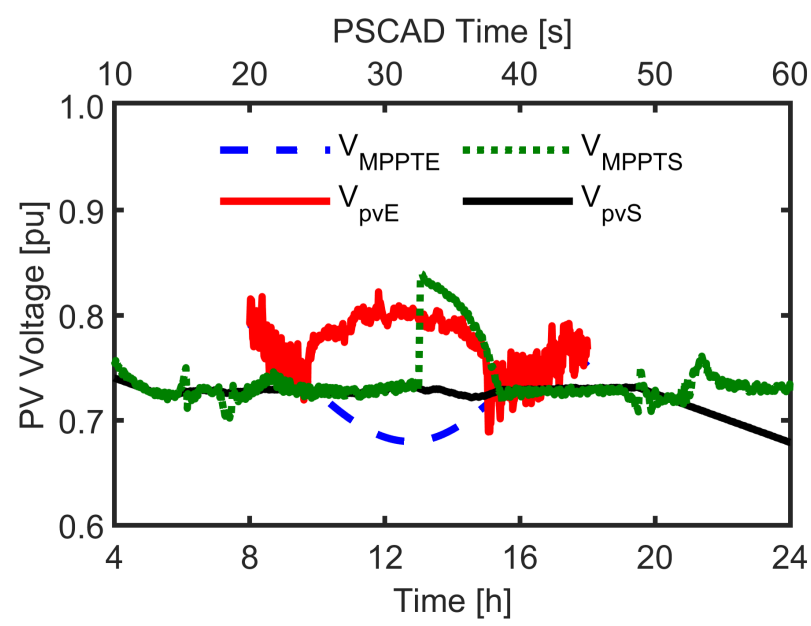

Figure 13. The PV array terminal voltages and MPPT references. The field implemented setup deviates from its MPPT reference during periods of excess irradiance, while the proposed setup switches to power curtailment mode only at $13 \mathrm{~h}$ due to BESS unavailability. Where, $V_{p v E}, V_{M P P T E}, V_{p v S}$, and $V_{M P P T S}$ represents the PV array voltage and MPPT reference for the experimental and proposed setup at $V_{\text {base }}=0.89 \mathrm{kV}$, respectively.

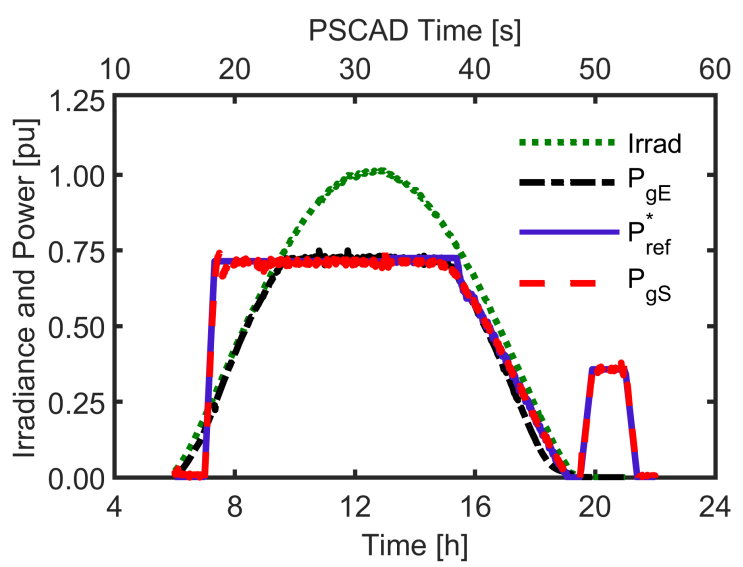

Figure 14. The system ac output power and experimental irradiance data (irrad) for the proposed $\left(P_{g S}\right)$ and field implemented systems $\left(P_{g E}\right)$. At approximately $19 \mathrm{~h}$ when PV power is unavailable, the BESS discharges independently to the grid. The $\operatorname{irrad} d_{\text {base }}=1000 \mathrm{~W} / \mathrm{m}^{2}, P_{\text {base }}=1.4 \mathrm{MW}$.

For the example day considered, the field implemented system switches from the MPPT mode to constant power operation at approximately $10 \mathrm{~h}$, forcing the PV array voltage to deviate towards open circuit and away from its MPP reference, leading potentially to unstable operating points [24].

A single section of the multi-MW PV system is simulated in PSAD/EMTDC under multiple operation modes for the same example day, in order to evaluate the expected transients during transitions and validate the model operation(Fig. 11). The $P_{r e f}^{*}$ was calculated to illustrate diverse operation modes of the proposed system. Also, the BESS was set to be unavailable between $13 \mathrm{~h}-19.5 \mathrm{~h}$ to validate the system performance and transient stability (Fig. 12) . The PSCAD/EMTDC simulation was accelerated such that the $1 \mathrm{~s}$ PSCAD time represents $24 \mathrm{~min}$ real-time.

The reference active power was controlled for constant power with a ramp rate of $10 \% / \mathrm{min}$. In order to maintain the PV array at the MPP, the BESS charges during the periods when $P_{r e f}^{*}$ is less than the available PV power and discharges otherwise, such that the inverter output corresponds to its reference. 


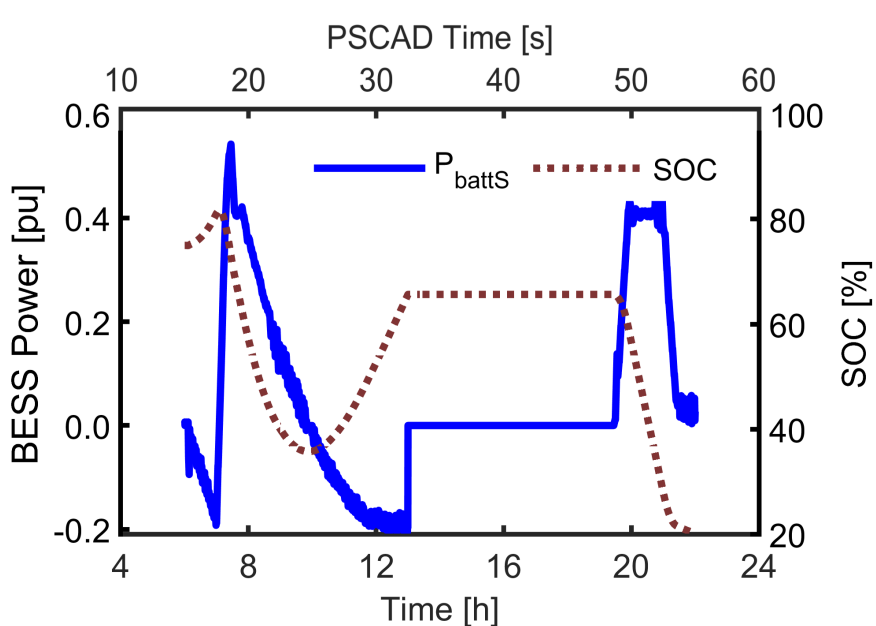

Figure 15. Battery net power flow and state of charge (SOC). The BESS charges and discharges in other to maintain the system ac output at the reference value. The BESS was unavailable between $13 \mathrm{~h}$ and $19.5 \mathrm{~h}$, and later discharges to the grid till $20 \%$ SOC.

At approximately $13 \mathrm{~h}$, the BESS system is fully charged, and therefore considered to become unavailable, and the system transitions into a different operation mode, where the dc-dc converter is inactive and the inverter switches to MPPT mode. Similar to the field implemented system, the simulated system operates at constant power mode during periods of excess irradiance, in which it curtails the additional power that would otherwise be stored in the BESS. Therefore, the PV array terminal voltage can be observed to deviate from its MPP reference during periods of surplus power availability and returns when the irradiance is below $714 \mathrm{~W} / \mathrm{m}^{2}$ (fig. 13 . It may be noted that the fully charged BESS can be used to supply the power deficit when the power available from the PV system is lower than the inverter ac rating.

During the late hours of the day when the irradiance is nearly zero and BESS is available, the system was operated to discharge independently, and reference active power calculated for the BESS to provide grid ancillary services (Fig. 14). Close to $19.5 \mathrm{~h}$, the BESS was operated to supply power to the grid to support the evening peak power demand. For simplicity, during this period, the battery dc-dc converter was regulated to maintain the dc-link voltage at $0.65 \mathrm{kV}$, while the inverter maintained the real power output at the reference value (Fig. $15)$.

As an example, following the experimental study previously presented, the available $1 \mathrm{MW} / 2 \mathrm{MWh}$ battery unit with a larger $\mathrm{PV}$ array of $1.54 \mathrm{MW}$ per section for the best weather condition is capable of producing $11.75 \mathrm{MWh}$ with the $1 \mathrm{MW}$ inverter, hence increasing the system capacity factor by $20.4 \%$. It may be noted that the increase in the system capacity factor may vary from site to site, and is expected to be higher for areas with high natural solar resources.

\section{PV Power SMOothing}

Battery energy storage systems may be employed on a cloudy day, to smooth the PV output power variation, in order to improve the delivered power quality, meet grid ramp

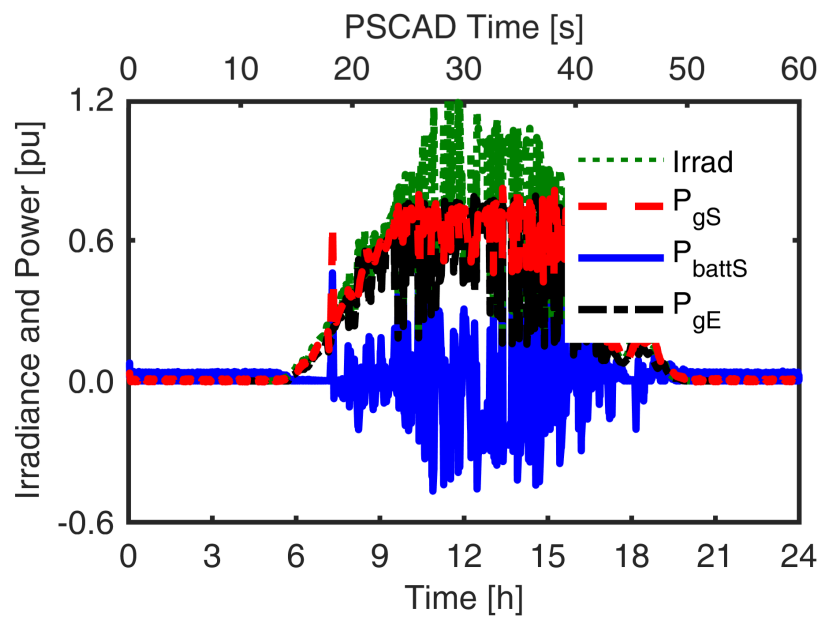

Figure 16. PV output power smoothing over a cloudy day; Per unit ac output power and experimental irradiance data (irrad) for the proposed $\left(P_{g S}\right)$ and field implemented systems $\left(P_{g E}\right)$, where $P_{b a t t S}$ represents the battery dc output power. $\operatorname{irrad}$ base $=1000 \mathrm{~W} / \mathrm{m}^{2}$ and $P_{\text {base }}=1.4 \mathrm{MW}$.

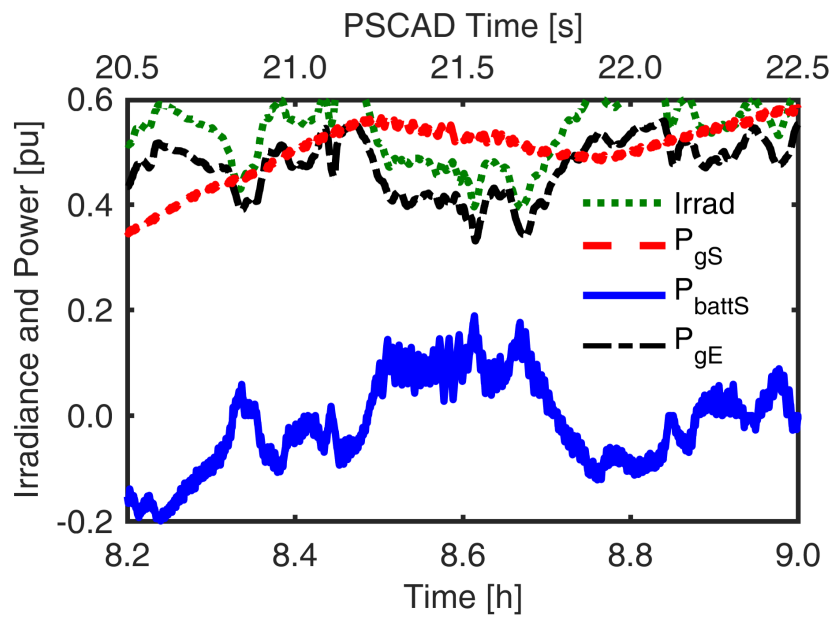

Figure 17. A zoomed-in representation of cloudy day power variation for experimental and simulated results. Battery charges and discharge at high frequency in order to reduce PV ramp rate while maintaining PV array voltage at MPP reference.

rate limitations and limit potential frequency deviations. In the case of multi-MW PV systems, sudden changes in the output power due to cloud movement can potentially induce severe voltage fluctuations leading to grid stability issues [24]. Utility companies with high renewable energy penetration often limit their maximum allowable ramp rate to $10 \%$ per minute, based on the system's rated capacity [25]. Different methods of curtailing the PV system real power output ramp rate through modified MPPT algorithms have been proposed [26], [27]. These methods lead to increased computational burdens, reduction in energy produced by the PV system and also require accurate weather forecasting devices. For this approach, the reference real power output of the PV inverter $\left(P_{r e f}^{M A}\right)$ is computed using a moving average (MA) technique to determine the sample mean of the saturated PV output estimated as: 
$P_{r e f}^{M A}(t)=\frac{P_{d c E}(t)+P_{d c E}(t-1)+\ldots+P_{d c E}(t-\Delta+1)}{\Delta}$,

where, $P_{r e f}^{M A}$ is the smooth PV power output; $P_{d c E}$, the PV system $\mathrm{dc}$ output power; $\mathrm{t}$, the time and $\Delta$, the number of considered points. For this study, the proposed system operation over a cloudy day was analyzed using irradiance data retrieved from two weather stations on the LG\&E and KU 10MW universal solar facility and simulated on a $\mathrm{PSCAD}^{T M} / \mathrm{EMTDC}^{T M}$ accelerated time scale. The moving average sample data was computed over 1000s, which reduced the maximum PV system ramp rate from $56.31 \% / \mathrm{min}$ to 4.15\%/min maximum (Fig. 16).

The BESS is controlled to supply the power difference between the available PV power and the computed moving average power of the PV system (Fig. 17). The field implemented $1 \mathrm{MW} / 2 \mathrm{MWh}$ BESS requires $0.40 \mathrm{MWh}$ energy in order to smooth the output power of the PV system while the proposed configuration smooths the PV output power, maintains the PV array at its MPP and provides additional storage energy of $0.74 \mathrm{MWh}$ to the battery which may be supplied to the grid at later hours.

\section{CONCLUSION}

This paper proposes a method for integrating battery storage into multi-MW grid-connected PV systems through the use of a dc-dc converter, capable of simultaneously operating as a charge controller and MPPT device. Advantages of such a configuration include increased total energy output of the PV system, improved control of the PV system dc-link voltage during power curtailment, and higher system efficiency as compared with other commonly used approaches with multiple power converters. Furthermore, the proposed approach provides a relatively low cost for battery integrated PV systems without the need for an additional dc-dc converter for MPPT optimal control.

A general approach for sizing dc-bus connected batteries to reduce the annual curtailed energy from utility-scale PV farms is developed. This approach evaluates the minimum battery size which can achieve substantial reductions in the annual solar energy curtailed. It was found that at the LG\&E and KU site, a BESS power to energy capacity ratio of approximately 1:3 leads to substantial savings. Furthermore, a $1 \mathrm{MW} / 2 \mathrm{MWh}$ battery is capable of retrieving up to $360 \mathrm{MWh}$ of the PV curtailed energy.

The detailed technical benefits of the proposed configuration with respect to $\mathrm{PV}$ output power smoothing and variable power generation were illustrated through $\mathrm{PSCAD}^{T M} / \mathrm{EMTDC}^{T M}$ simulations of two case studies with irradiance variation for a clear and cloudy day. Furthermore, the performance and steady operation of the proposed dc-dc converter and transition into multiple operation modes was verified. In order to validate the capabilities and effectiveness of the proposed system and controls, its simulated performance was compared with computed and experimental data from the LG\&E and KU E.W. Brown universal solar facility, which houses a 10MW $\mathrm{PV}$ farm and a $1 \mathrm{MW} / 2 \mathrm{MWh}$ BESS. The results show that for
PV installations in an area with good solar PV resources and a lot of clear days, an increase in the annual capacity factor of up to $20 \%$ is possible with a dc-bus connected battery. At the other end, a negligible increase in the capacity factor for areas with limited solar availability is expected.

\section{ACKNOWLEDGMENT}

The support of University of Kentucky, the L. Stanley Pigman endowment, of the SPARK Laboratory, Power and Energy Institute of Kentucky (PEIK), and of LG\&E and KU is gratefully acknowledged.

\section{REFERENCES}

[1] F. Blaabjerg and D. M. Ionel, "Renewable energy devices and systems - state-of-the-art technology, research and development, challenges and future trends," Electric Power Components and Systems, vol. 43, no. 12, pp. 1319-1328, 2015.

[2] F. Blaabjerg and D. M. Ionel, Renewable Energy Devices and Systems with Simulations in MATLAB $®$ and ANSYS $囚 . \quad$ CRC Press, 2017.

[3] T. F. Wu, C. H. Chang, L. C. Lin, and C. L. Kuo, "Power loss comparison of single- and two-stage grid-connected photovoltaic systems," vol. 26 , no. 2, June 2011, pp. 707-715.

[4] Y. Zhu, J. Yao, and D. Wu, "Comparative study of two stages and single stage topologies for grid-tie photovoltaic generation by PSCAD/EMTDC," in 2011 International Conference on Advanced Power System Automation and Protection, vol. 2, Oct 2011, pp. 13041309.

[5] S. Jain, R. Karampuri, and V. T. Somasekhar, "An integrated control algorithm for a single-stage pv pumping system using an open-end winding induction motor," IEEE Transactions on Industrial Electronics, vol. 63, no. 2, pp. 956-965, Feb 2016.

[6] O. M. Akeyo, V. Rallabandi, and D. M. Ionel, "Multi-MW solar PV pumping system with capacity modulation and battery voltage support," in 2017 IEEE 6th International Conference on Renewable Energy Research and Applications (ICRERA), Nov 2017, pp. 423-428.

[7] A. Merabet, K. T. Ahmed, H. Ibrahim, R. Beguenane, and A. M. Y. M. Ghias, "Energy management and control system for laboratory scale microgrid based wind-pv-battery," IEEE Transactions on Sustainable Energy, vol. 8, no. 1, pp. 145-154, Jan 2017.

[8] J. Sachs and O. Sawodny, "A two-stage model predictive control strategy for economic diesel-PV-battery island microgrid operation in rural areas," IEEE Transactions on Sustainable Energy, vol. 7, no. 3, pp. 903-913, July 2016.

[9] V. Karthikeyan and R. Gupta, "Varying phase angle control in isolated bidirectional dc 8211;DC converter for integrating battery storage and solar PV system in standalone mode," IET Power Electronics, vol. 10, no. 4, pp. 471-479, 2017.

[10] Y. Chang, Y. Feng, W. Chiang, R. Chang, M. Chiueh, and T. Holtz, "5kw dc-coupling distribution power generation system based on photovoltaic and aqueous hybrid ion battery," in 2017 IEEE 3rd International Future Energy Electronics Conference and ECCE Asia (IFEEC 2017 - ECCE Asia), June 2017, pp. 1719-1724.

[11] Kyohei Kurohane, T. Senjyu, Akie Uehara, A. Yona, T. Funabashi, and Chul-Hwan Kim, "A hybrid smart ac/dc power system," in 2010 5th IEEE Conference on Industrial Electronics and Applications, June 2010, pp. 764-769.

[12] T. Ma, M. H. Cintuglu, and O. A. Mohammed, "Control of a hybrid ac/dc microgrid involving energy storage and pulsed loads," IEEE Transactions on Industry Applications, vol. 53, no. 1, pp. 567-575, Jan 2017.

[13] M. Rezkallah, A. Hamadi, A. Chandra, and B. Singh, "Real-time HIL implementation of sliding mode control for standalone system based on pv array without using dumpload," IEEE Transactions on Sustainable Energy, vol. 6, no. 4, pp. 1389-1398, Oct 2015.

[14] O. Akeyo, V. Rallabandi, N. Jewell, and D. M. Ionel, "Improving the capacity factor and stability of multi-mw grid connected pv systems with results from a $1 \mathrm{mw} / 2 \mathrm{mwh}$ battery demonstrator," in 2018 IEEE Energy Conversion Congress and Exposition (ECCE), Sep. 2018, pp. 2504-2509. 
[15] V. Rallabandi, O. M. Akeyo, N. Jewell, and D. M. Ionel, "Incorporating battery energy storage systems into multi-mw grid connected pv systems," IEEE Transactions on Industry Applications, vol. 55, no. 1, pp. 638-647, Jan 2019.

[16] H. Mahmood, D. Michaelson, and J. Jiang, "Strategies for independent deployment and autonomous control of PV and battery units in islanded microgrids," IEEE Journal of Emerging and Selected Topics in Power Electronics, vol. 3, no. 3, pp. 742-755, Sept 2015.

[17] N. A. DiOrio, J. M. Freeman, and N. Blair, "Dc-connected solar plus storage modeling and analysis for behind-the-meter systems in the system advisor model," in 2018 IEEE 7th World Conference on Photovoltaic Energy Conversion (WCPEC) (A Joint Conference of 45th IEEE PVSC, 28th PVSEC 34th EU PVSEC), June 2018, pp. 3777-3782.

[18] M. O. Badawy and Y. Sozer, "Power flow management of a grid tied PV-battery system for electric vehicles charging," IEEE Transactions on Industry Applications, vol. 53, no. 2, pp. 1347-1357, March 2017.

[19] N. Saxena, I. Hussain, B. Singh, and A. L. Vyas, "Implementation of a grid-integrated PV-battery system for residential and electrical vehicle applications," IEEE Transactions on Industrial Electronics, vol. 65, no. 8, pp. 6592-6601, Aug 2018.

[20] P. Satapathy, S. Dhar, and P. K. Dash, "Stability improvement of PVBESS diesel generator-based microgrid with a new modified harmony search-based hybrid firefly algorithm," IET Renewable Power Generation, vol. 11, no. 5, pp. 566-577, 2017.

[21] R. Teichmann and S. Bernet, "A comparison of three-level converters versus two-level converters for low-voltage drives, traction, and utility applications," IEEE Transactions on Industry Applications, vol. 41, no. 3, pp. 855-865, May 2005.

[22] Utility Scale Solar Inverter, Power Electronics.

[23] S. Chen, T. Huang, S. S. Ng, K. Lin, M. Du, Y. Kang, K. Chen, C. Wey, Y. Lin, C. Lee, J. Lin, and T. Tsai, "A direct ac-dc and dc-dc cross-source energy harvesting circuit with analog iterating-based mppt technique with 72.5efficiency," IEEE Transactions on Power Electronics, vol. 31, no. 8, pp. 5885-5899, Aug 2016.

[24] A. Sangwongwanich, Y. Yang, and F. Blaabjerg, "A cost-effective power ramp-rate control strategy for single-phase two-stage grid-connected photovoltaic systems," in 2016 IEEE Energy Conversion Congress and Exposition (ECCE), Sept 2016, pp. 1-7.

[25] D. Cormode, A. D. Cronin, W. Richardson, A. T. Lorenzo, A. E. Brooks, and D. N. DellaGiustina, "Comparing ramp rates from large and small PV systems, and selection of batteries for ramp rate control," in 2013 IEEE 39th Photovoltaic Specialists Conference (PVSC), June 2013, pp. 1805-1810.

[26] W. A. Omran, M. Kazerani, and M. M. A. Salama, "Investigation of methods for reduction of power fluctuations generated from large grid-connected photovoltaic systems," IEEE Transactions on Energy Conversion, vol. 26, no. 1, pp. 318-327, March 2011.

[27] R. Yan and T. K. Saha, "Power ramp rate control for grid connected photovoltaic system," in 2010 Conference Proceedings IPEC, Oct 2010, pp. $83-88$

Oluwaseun M. Akeyo (S'16) received the M.S. degree in electrical engineering from University of Kentucky, Lexington, KY and the B. Eng degree in electrical and electronics engineering from Abubakar Tafawa Balewa University (ATBU), Bauchi, Nigeria in 2017 and 2014, respectively. He is currently a Ph.D. candidate in electrical engineering at University of Kentucky, where he also serves as a research assistant in the SPARK Laboratory. He won the Best Presentation award at the 2018 FEEDER Summer Program and the Best Poster Paper award at the 2016 IEEE International Conference on Renewable Energy Research and Applications, ICRERA. His research focuses on power systems, power electronics, battery energy storage, and renewable energy sources.
Vandana Rallabandi (M'17-SM'19) is a Lead Engineer at GE Research in Niskayuna, NY, USA. Previously, she was a Postdoctoral Researcher with the SPARK Lab, University of Kentucky, Lexington, KY, USA, and a Research Engineer with the GE Research Center, Bangalore, India. Her research interests include electric machines, power electronics drives, renewable energy devices and systems, energy storage, and power systems. She received the masters and Ph.D. degrees from the Indian Institute of Technology Bombay, Mumbai, India.

Nicholas Jewell (S'07-M'15-SM'18) received the Doctor of Philosophy degree in electrical engineering from the University of Louisville, Louisville, KY, USA, in 2014. He is a Senior Electrical Engineer with the Electrical Engineering and Planning Department, Louisville Gas and Electric and Kentucky Utilities (LG\&E and KU). At LG\&E and KU, he serves as the company subject matter expert in areas such as distribution planning, power systems analysis, and distributed energy resources (DER). Dr. Jewell's primary focus is on implementing advanced DER strategies and defining and executing a multi-year strategic roadmap pertaining to distribution hosting capacity, distribution system interconnection requirements, customer usage behavior, and system analysis regarding DER impacts to protection systems. He has been an author or co-author for a number of industry publications, has received several Tech Transfer Awards from the Electric Power Research Institute, and has one patent disclosure. Additionally, he was named a Top Innovator by Public Utilities Fortnightly in 2018. Dr. Jewell is a Registered Project Management Professional.

Dan M. Ionel (M'91-SM'01-F'13) received the M.Eng. and Ph.D. degrees in electrical engineering from the Polytechnic University of Bucharest, Bucharest, Romania.

His doctoral program included a Leverhulme Visiting Fellowship with the University of Bath, Bath, U.K. Dr. Ionel was a Postdoctoral Researcher with the SPEED Laboratory, University of Glasgow, Glasgow, U.K. He is currently a Professor of electrical engineering and the L. Stanley Pigman Chair in Power with the University of Kentucky, Lexington, KY, USA, where he is also the Director of the Power and Energy Institute of Kentucky and of the SPARK Laboratory. He previously worked in industry, most recently as a Chief Engineer for Regal Beloit Corp., Grafton, WI, USA, and, before that, as the Chief Scientist for Vestas Wind Turbines. Concurrently, he was also a Visiting and Research Professor with the University of Wisconsin and Marquette University, Milwaukee, WI, USA.

He holds more than thirty patents, including a medal winner at the Geneva Exhibition of Inventions, authored and coauthored more than two hundred technical papers, including five that received IEEE awards, and two books. $\mathrm{He}$ has contributed to technology developments with long lasting industrial impact.

Dr. Ionel was the Inaugural Chair of the IEEE Industry Applications Society Renewable and Sustainable Energy Conversion Systems Committee, an Editor for the IEEE TRANSACTIONS ON SUSTAINABLE ENERGY, the Chair of the IEEE Power and Energy Society Electric Motor Subcommittee and of the IEEE WG 1812, and the General Chair of the IEEE 2017 Anniversary Edition of the International Conference on Electrical Machines and Drives (IEMDC). He is the Editor-in-Chief for the Electric Power Components and Systems Journal, and the Chair of the Steering Committee for the IEEE IEMDC Conferences. 